\title{
Experimental investigation on the seismic damage behaviour of reinforced concrete columns and beams
}

\author{
L. Chen, X. Lu, H. Jiang \& J. Zheng \\ State Key Laboratory for Disaster Reduction in Civil Engineering, \\ Tongii University, Shanghai, China
}

\begin{abstract}
The enormous loss of lives and property during the recent, strong earthquake in Sichuan, China reminds the public again of the extreme importance of seismic performance of engineering structures. As generally accepted as a promising direction, the performance-based seismic design (PBSD) method requires deeper insight into structural damage behaviours during strong earthquakes. The research in this paper was aimed at assessing the seismic performance of reinforced concrete columns and beams with varying design parameters. The main variables of the tested specimens included axial load ratio, shear-span ratio, lateral reinforcement ratio and longitudinal reinforcement ratio. It was found that the progression of damage was generally similar, and the flexural behaviour was dominant in all specimens with only one exception, which was designed according to early non-seismic design code. The influence of design parameters on ductility and damage behaviour are investigated, and it turns out that the axial load ratio and shear-span ratio affect ductility and cracking progress remarkably. The longitudinal reinforcement ratio has only a limited effect on the ductility of columns, but evidently affects the ductility of beams. The lateral reinforcement ratio seems to be a less important factor affecting column cracking behaviour, and it has drift-related effect on the cracking of beams. It is expected that these relationships can be utilized for the purpose of direct damage control in seismic design processes.
\end{abstract}

Keywords: seismic design, damage states; performance, reinforced concrete columns. 


\section{Introduction}

A major natural disaster faced by people, that of strong earthquakes, brings about extremely serious loss of lives and damage to structures and properties. On 12 May 2008 a great earthquake hit Sichuan Province, located in the western part of China, resulting in more than 80,000 deaths and immense economic losses. As accepted generally by the researchers of earthquake and structural engineering, the performance-based seismic design (PBSD) method provides a promising solution for the design of earthquake-resistant engineering structures [1]. The PBSD method allows structures to experience damage to certain contents during earthquakes, which necessitates the definition of certain damage levels corresponding to different performance objectives of structures. Up to now the frame structures still have extensive application in many kinds of buildings, and the performance of columns and beams is a key factor that influences the performance of the whole frame structures. Therefore, in order to control the damage levels of structures, it is of great importance to investigate the earthquake-induced damage behaviour of columns and beams.

In this paper, ten columns and three beams were designed according to Chinese codes of different times, and specimens were manufactured and tested at the State Key Laboratory for Disaster Reduction in Civil Engineering at Tongji University. Some hysteresis loops are provided, and the envelope curves are analyzed for comparing the influence of different parameters on the ductility of specimens. The failure modes, maximum crack width and maximum residual crack width of each specimen are compared within certain parameter groups for the purpose of determining the relationships between the damage process and design parameters.

\section{Experiment programme}

\subsection{Specimen design}

Former research indicates that the axial load ratio affects seismic performance of frame members remarkably. Wang et al [2] discussed the factors influencing column ductility based on a series of tests of single cantilever square columns, and consider the axial load ratio as the most influential parameter. Another major factor affecting column performance is the shear-span ratio, which Park [3] believes is the dominating factor governing the damage process and failure mode of members loaded simultaneously with bending moment and shear force. Generally when the shear-span ratio of a column is greater than three and the column is laterally confined adequately, the failure is dominated by flexural behaviour. This limit value is also adopted by the Chinese Code for the Design of Concrete Structures [4]. With the brittleness of shear failure taken into consideration, columns with a shear-span ratio of less than three are often avoided by designers. In this study, only columns or beams with a shear-span ratio greater than three are considered. Other factors also taken into account for the specimen design are the lateral reinforcement ratio, volumetric for column 
and area ratio for beam, and the longitudinal reinforcement ratio. Detailed information about each specimen is listed in Table 1.

Table 1: Design parameters of each specimen.

\begin{tabular}{ccccccccc}
\hline Specimen $n$ & $L / h$ & $\begin{array}{c}\rho_{v} \\
\text { or } \rho_{s}\end{array}$ & \multicolumn{2}{c}{$\begin{array}{c}\text { Lateral } \\
\text { reinforcement }\end{array}$} & $\rho_{l}$ & \multicolumn{2}{c}{$\begin{array}{c}\text { Longitudinal } \\
\text { reinforcement } \\
\text { Diameter }\end{array}$} \\
\hline C301 & 0.1 & 3 & $1.46 \%$ & 6.5 & 40 & $1.97 \%$ & 8 & 14 \\
$\mathrm{C} 303$ & 0.3 & 3 & $1.46 \%$ & 6.5 & 40 & $1.97 \%$ & 8 & 14 \\
$\mathrm{C} 305$ & 0.5 & 3 & $1.46 \%$ & 6.5 & 40 & $1.97 \%$ & 8 & 14 \\
$\mathrm{C} 307$ & 0.7 & 3 & $1.46 \%$ & 6.5 & 40 & $1.97 \%$ & 8 & 14 \\
$\mathrm{C} 505$ & 0.5 & 5 & $1.46 \%$ & 6.5 & 40 & $1.97 \%$ & 8 & 14 \\
$\mathrm{C} 705$ & 0.5 & 7 & $1.46 \%$ & 6.5 & 40 & $1.97 \%$ & 8 & 14 \\
$\mathrm{C} 505 \mathrm{~S}$ & 0.5 & 5 & $0.83 \%$ & 6.5 & 70 & $1.97 \%$ & 8 & 14 \\
$\mathrm{C} 505 \mathrm{D}$ & 0.5 & 5 & $2.15 \%$ & 8 & 40 & $1.97 \%$ & 8 & 14 \\
$\mathrm{C} 305 \mathrm{~L}$ & 0.5 & 3 & $1.46 \%$ & 6.5 & 40 & $1.00 \%$ & 8 & 10 \\
$\mathrm{C} 505 \mathrm{C}$ & 0.5 & 5 & $0.23 \%$ & 6.5 & 250 & $1.97 \%$ & 8 & 14 \\
$\mathrm{~B} 22 \mathrm{~S}$ & 0.0 & 4.8 & $0.50 \%$ & 8 & 100 & Top: $0.95 \%$ & 2 & 22 \\
& & & & & & Bottom: $0.50 \%$ & 2 & 16 \\
$\mathrm{~B} 25$ & 0.0 & 4.8 & $0.50 \%$ & 8 & 100 & Top: $1.94 \%$ & 3 & 25 \\
& & & & & & Bottom: $0.95 \%$ & 2 & 22 \\
$\mathrm{~B} 22$ & 0.0 & 4.8 & $1.00 \%$ & 8 & 50 & Top: $0.95 \%$ & 2 & 22 \\
\hline
\end{tabular}

Note: $n=N / f_{c} A_{g}$ is the nominal axial load ratio, where $N$ is axial load exerted during tests, $f_{c}=0.88 \times 0.76 \times \mu_{f_{c u}} / 1.4$ is the design value of concrete compression strength [5], and $\mu_{f_{c u}}$ is the mean value of cubic compression strength of material specimen. $A_{g}$ is the gross section area. $L / h$ is the shearspan ratio, where $L$ is specimen clear length and $h$ is the section height. $\rho_{v}$ and $\rho_{s}$ are the volumetric ratio and area ratio of Lateral reinforcement ratio. $\rho_{l}$ is the Longitudinal reinforcement ratio.

All the column specimens are of square section with an edge length of $250 \mathrm{~mm}$, and the beam specimens are rectangular in section with a section width of $200 \mathrm{~mm}$ and a section height of $400 \mathrm{~mm}$. Concrete cover is $25 \mathrm{~mm}$ thick, designed in accordance with the Chinese Code for Design of Concrete Structures. All the specimens are of the single cantilever type. The section and elevation drawings are provided in Figure 1.

\subsection{Materials}

The specimens were manufactured in the laboratory with ready-mixed concrete, and a number of concrete and rebar specimens were taken for material testing. 
The targeted concrete strength grade is C30. The tested material characteristics such as strength and elastic modulus are listed in Tables 2 and 3, where the characteristic values are acquired by averaging through all the material specimens.
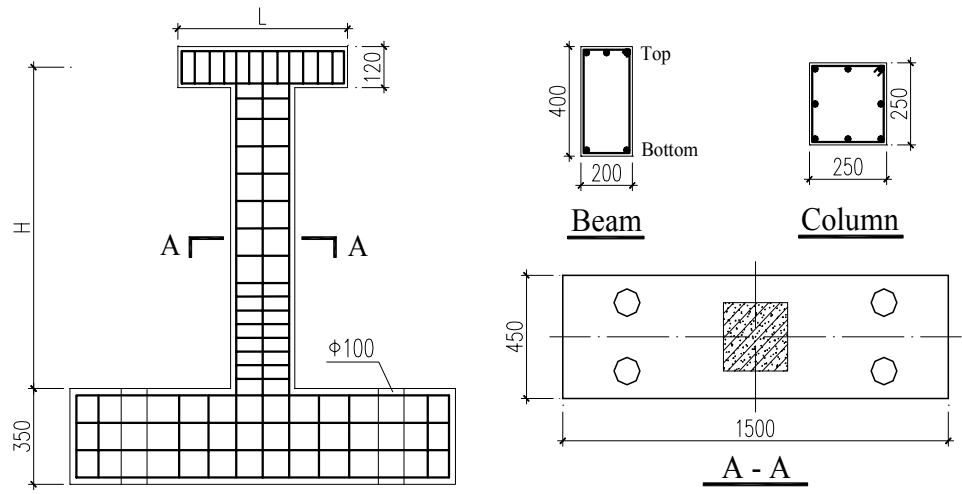

Figure 1: $\quad$ Section and elevation of specimen (length in $\mathrm{mm}$ ).

Table 2: $\quad$ Tested concrete characteristic values.

\begin{tabular}{ccc}
\hline $\begin{array}{c}\text { Cubic compression } \\
\text { strength } \mu_{f a}(\mathrm{MPa})\end{array}$ & $\begin{array}{c}\text { Axial compression } \\
\text { strength }(\mathrm{MPa})\end{array}$ & $\begin{array}{c}\text { Modulus of } \\
\text { elasticity }(\mathrm{MPa})\end{array}$ \\
\hline 30.30 & 22.20 & $3.04 \times 104$ \\
\hline
\end{tabular}

Table 3: $\quad$ Tested strength of rebar.

\begin{tabular}{ccc}
\hline Diameter of rebar $(\mathrm{mm})$ & Yield strength $(\mathrm{MPa})$ & Ultimate strength $(\mathrm{MPa})$ \\
\hline 10 & 338.33 & 488.33 \\
14 & 355.00 & 520.00 \\
16 & 350.00 & 506.67 \\
22 & 335.00 & 500.00 \\
25 & 391.47 & 555.61 \\
6.5 & 423.33 & 463.33 \\
8 & 408.33 & 481.67 \\
\hline
\end{tabular}

\subsection{Test procedure}

Figure 2 illustrates the detailed test set-up along with its simplified mechanical drawing. The axial load was computed in advance according to the design value of concrete strength, section area and axial load ratio, and exerted on the single cantilever specimen, maintaining constant through the whole testing process. Then, horizontal load was applied by the actuator. When the horizontal load is relatively small, say less than $75 \%$ of the yield force of specimen, the test was controlled by actuator force. While approaching yielding of the specimen, it was transferred to the displacement-control stage. After yielding of the longitudinal 
rebar, three cycles of loading and unloading were conducted for each displacement amplitude in order to observe the stiffness degradation behaviour. During the whole test processes, the tip drift, horizontal force, strain of longitudinal and lateral rebar and concrete crack width were measured by responding instruments. Maximum crack width and maximum residual width were measured at the peak horizontal force or displacement points and the zeroforce points within each loading and unloading cycle, respectively. The instrument for measuring crack width has a measurement range from $0.02 \mathrm{~mm}$ to $8 \mathrm{~mm}$. At the first appearance of cracks the width was often less than $0.02 \mathrm{~mm}$, thus only the distribution of them was recorded. For cracks wider than $8 \mathrm{~mm}$, the width was estimated by using a steel ruler. Displacement of the anchoring beam at the bottom of each specimen, although usually negligible, was also monitored by a linear variable displacement transducer (LVDT), so that the net drift of specimen tip can be obtained.

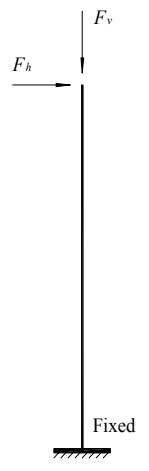

(a)

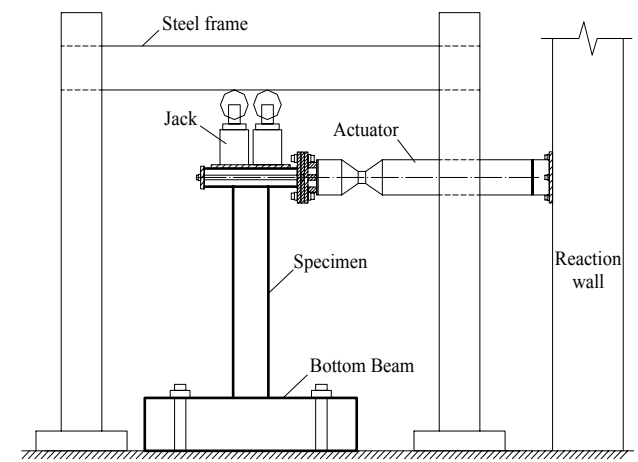

(b)

Figure 2: $\quad$ Experimental configuration. (a) Mechanical model. (b) Test set-up.

\section{Test results}

\subsection{Overview}

Flexural behaviour exhibits dominantly during the tests of all specimens except for the column C505C, which was designed according to non-seismic code with a hoop spacing of $250 \mathrm{~mm}$. At the emergence of cracks on the tension side, the width of all cracks was below $0.02 \mathrm{~mm}$ and the spacing between cracks was approximate to the hoop spacing. As the horizontal displacements increase, the cracks develop wider. However, the maximum crack width during the second and third cycle was roughly the same as that during the first cycle, and there are rarely new cracks emerging during repeated cycles of the same displacement amplitude. After yielding of longitudinal rebars, the concrete cover at the bottom of the specimens begins spalling. Cover spalling continues until buckling of the longitudinal rebars and crushing of the concrete core. Typical flexural failure is shown in Figure 3. 
As shown in Table 1, the lateral reinforcement of specimen $\mathrm{C} 505 \mathrm{C}$ is below the minimum requirement stipulated by Chinese seismic design code [5]. The main diagonal crack appears during the $24 \mathrm{~mm}$ displacement cycle, and develops sharply. As illustrated in Figure 4, its width finally reaches $15.5 \mathrm{~mm}$, and buckling is found for all the longitudinal rebars below the first stirrup. The corner longitudinal rebar even buckles between the first and second stirrup, indicating the weak confining action of lateral reinforcement.
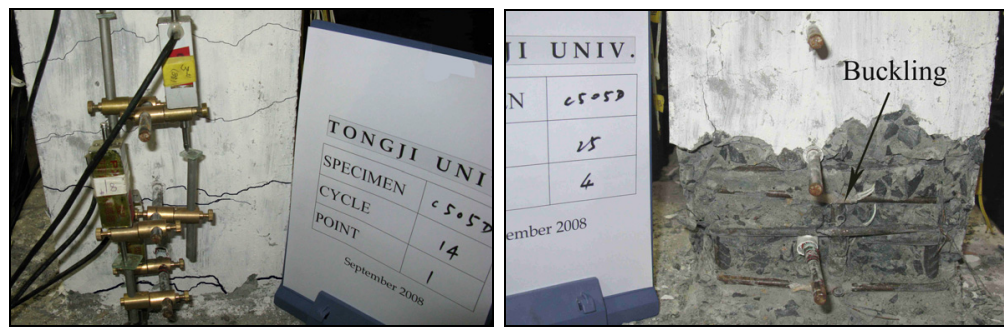

Figure 3: $\quad$ Typical flexural failure.

(a)

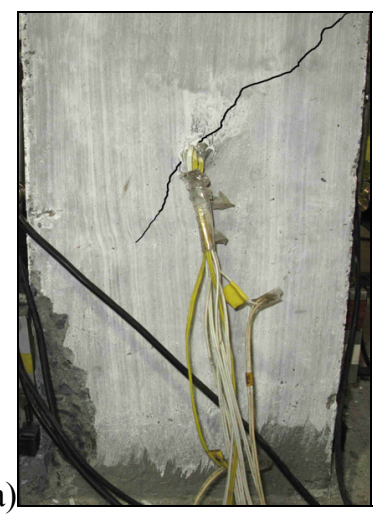

(b)

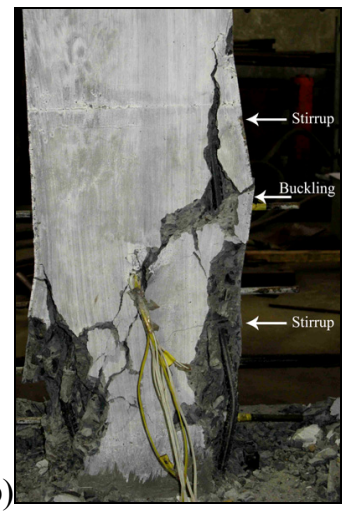

Figure 4: $\quad$ Remarkable shear effect (C505C): (a) formation of diagonal crack; (b) developing of diagonal crack.

Compared to the symmetric damage in opposite sides of column specimens, the damage to beam specimens is observed with evident asymmetry, as shown in Figure 5. Owing to the fact that longitudinal reinforcement of top side of the beam specimen is about twice as much as that of the bottom side, cover spalling takes place firstly on the weakly reinforced bottom side and so does the concrete core crushing. The top side, however, keeps an intact concrete cover until tests finished. The reason is that when the top side is in compression, the height of section compression region is fairly small because of the great disparity of longitudinal reinforcement in two sides and no vertical load exerted. Therefore, the edge concrete strain of the compression region does not reach its ultimate value in flexure. 

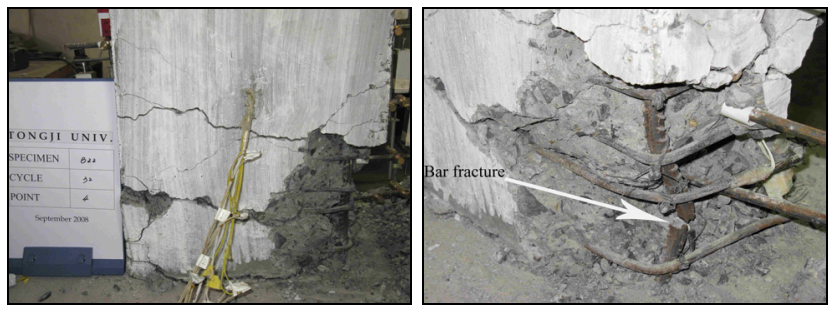

Figure 5: Asymmetric damage behaviour in beam specimen.
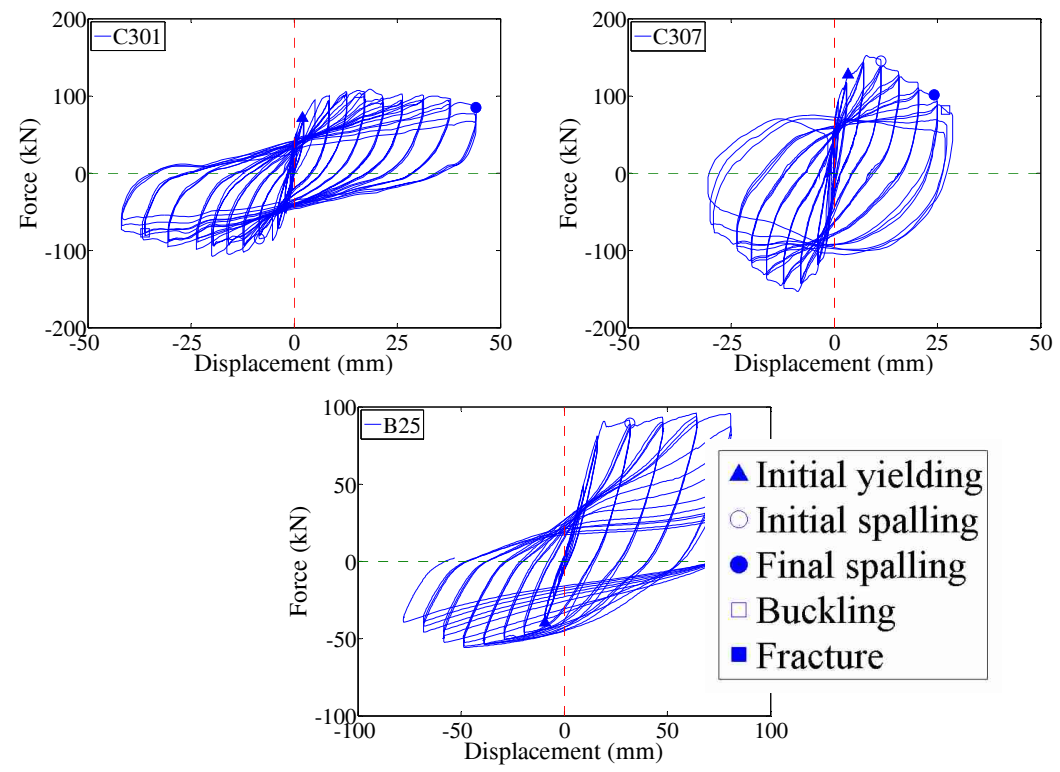

Figure 6: Hysteresis loops of some specimens.

\subsection{Hysteresis loops}

When the axial load ratio is relatively low, the horizontal force-displacement curves are generally ascending during the loading cycle. However, as the axial load ratio increases, the horizontal force-displacement curve begins to drop down after arriving at the peak force when loading. This phenomenon is shown in Figure 6, where some damage points are also marked in the hysteresis loops. For the beam specimens, hysteresis loops indicate some extent of pinching effect after final spalling of cover concrete. This may be because the loss of concrete cover results in evident bond-slip of longitudinal rebars at the bottom of the specimens, and the confinement for longitudinal rebars brought by stirrups is weakened. Strength degradation is pronounced for the beam specimens when the top side (more longitudinal rebars) is in tension, compared with that in other situations. Considering the asymmetric damage behaviour observed in beams, 
this may be explained by the rapidly-progressing concrete core crushing at the bottom side (less longitudinal rebars) of beams, which results in the shortening of the section internal lever arm.

\subsection{Ductility evaluation}

Ductility is the capability of structures or members to deform without significant drop down of load carrying capacity, which is often defined by the so-called ductility coefficient:

$$
\mu=\Delta_{u} / \Delta_{y},
$$

where $\Delta_{u}$ and $\Delta_{y}$ are the ultimate and yielding deformation, respectively. So far there have been numerous definitions for these two values [6-9]. Different methods of definition lead to a remarkable difference of ductility coefficient. Based on careful analysis on abundant results of many kinds of laboratory tests on structures and members, Park concludes and points out several definitions of ultimate and yielding deformation, which are in good agreement with test results [10]. In this paper the yielding deformation is determined by the first yielding of longitudinal reinforcement, or by the intersection of the horizontal line at maximum force with the straight line passing the origin and the $75 \%$ maximum force point on the envelope curve, whichever is less. The ultimate deformation is defined by the point on the descending section of the envelope curve with a $15 \%$ force drop. For the purpose of clearness, these definitions are illustrated in Figure 7. The ductility of each specimen is computed for two loading directions, respectively and the mean value of them is chosen as the ductility of the specimen.

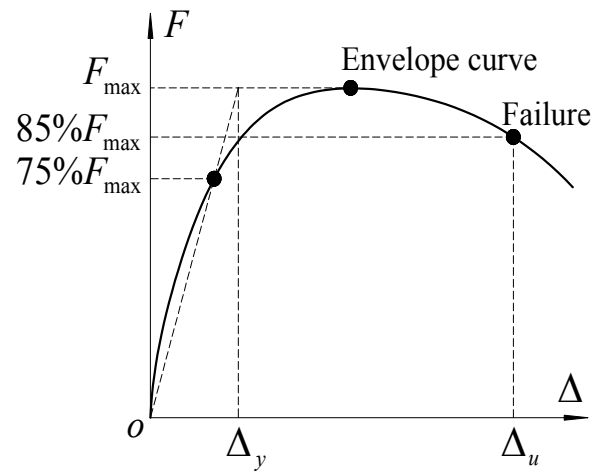

Figure 7: Definitions for ultimate and yielding deformation.

Specimens are grouped into several series according to axial load ratio, shearspan ratio and so on, so that the influence of each parameter on ductility can be studied without any change in other parameters. As shown in Figure 8, there are six groups available for the comparative investigation, four for columns and two for beams. In the axial load ratio group, ductility drops $42 \%$ from 8.27 to 4.81 
when the axial load ratio increases from 0.1 to 0.7 , indicating the significant effect of axial load ratio on ductility. A similar situation can be found in the shear-span ratio group, which consists of specimens C305, C505 and C705 with $\mathrm{L} / \mathrm{h}$ of 3,5 and 7 respectively. With the shear-span ratio increasing from 3 to 7 , the corresponding column ductility decreases from 6.46 to 3.53 with a $45 \%$ drop. When it comes to the volumetric lateral reinforcement ratio, it seems that for the well-confined columns, such as C505S, C505 and C505D, increasing lateral reinforcement does not improve ductility remarkably. However, the picture is different for the non-seismic-designed columns, say C505C, which yields much smaller ductility than the seismic-designed columns. The longitudinal reinforcement ratio seems to influence column ductility slightly. The ductility of specimen $\mathrm{C} 305 \mathrm{~L}$ drops $9 \%$ from 7.14 to 6.46 of specimen $\mathrm{C} 305$ with longitudinal reinforcement ratio increasing from $1.00 \%$ to $1.97 \%$.
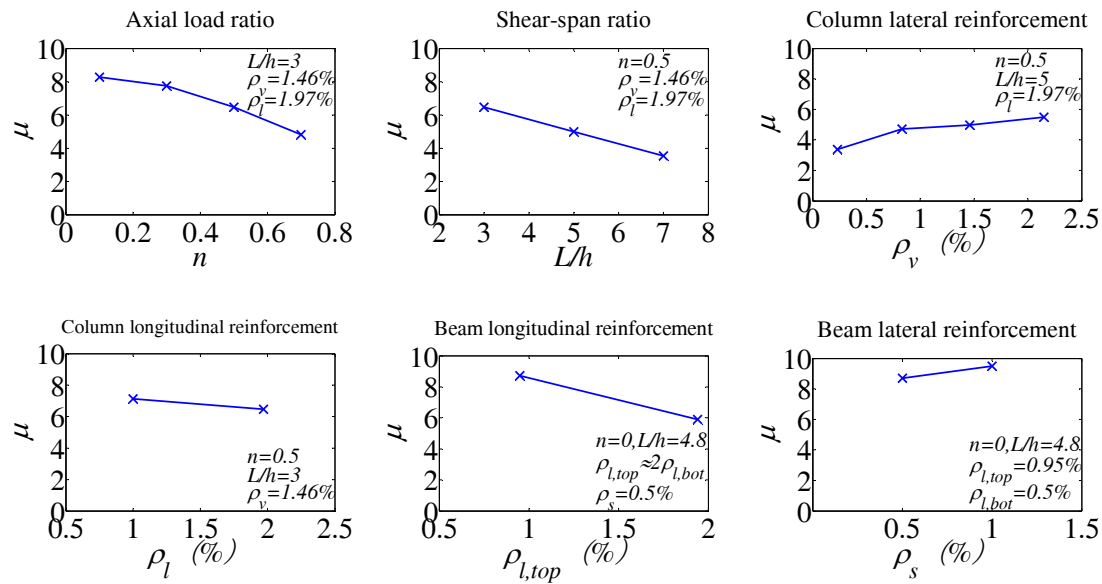

Figure 8: Influence of parameters on ductility.

The beam specimens are grouped into two series. Because the longitudinal reinforcement of the top side is approximate to two times that of the bottom side, the reinforcement ratio of the top side is chosen as the $\mathrm{x}$-coordinate. As the top longitudinal reinforcement ratio nearly doubles itself, ductility drops $32 \%$, demonstrating the pronounced effect of the longitudinal reinforcement ratio on ductility. While the area ratio of lateral reinforcement doubles, ductility increases $9 \%$. Hence the lateral reinforcement level seems to be a less significant factor for beam ductility.

\subsection{Crack width}

The maximum crack width and maximum residual crack width of each specimen, represented by $w_{\max }$ and $w_{m, r s d}$ respectively, are provided in relation to drift angle in Figures 9 and 10, respectively. As a whole these two variables are monotonic increasing functions of specimen drift angles. The axial load ratio 
appears to be the most important factor for crack developing. Both the maximum crack width and the maximum residual width decrease with the increasing of axial load ratio, demonstrating the restraining effect on crack opening and promoting an effect on crack closing of the axial load.
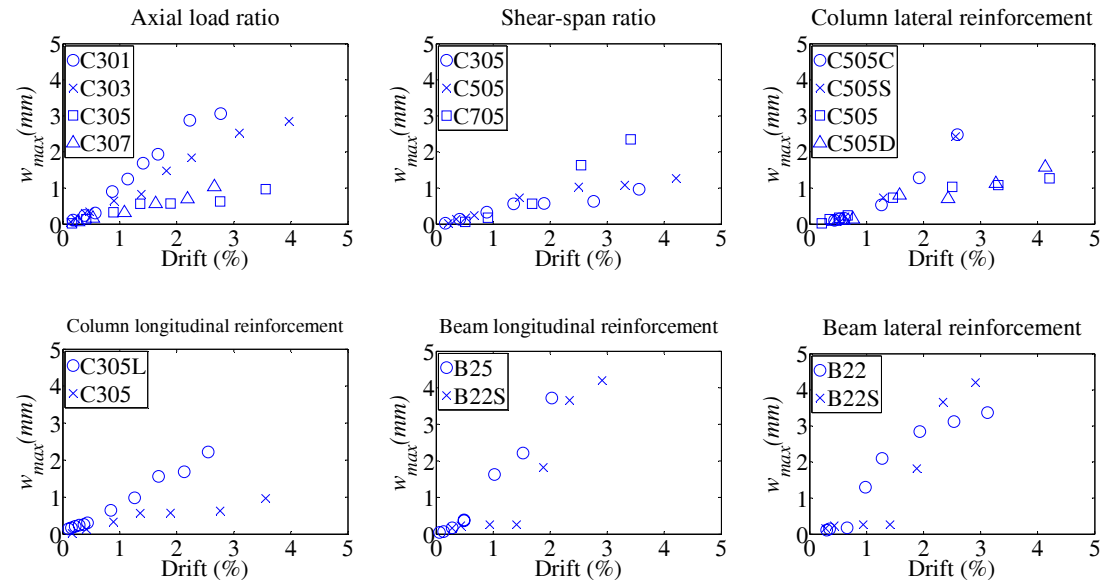

Figure 9: Maximum crack width of specimens.
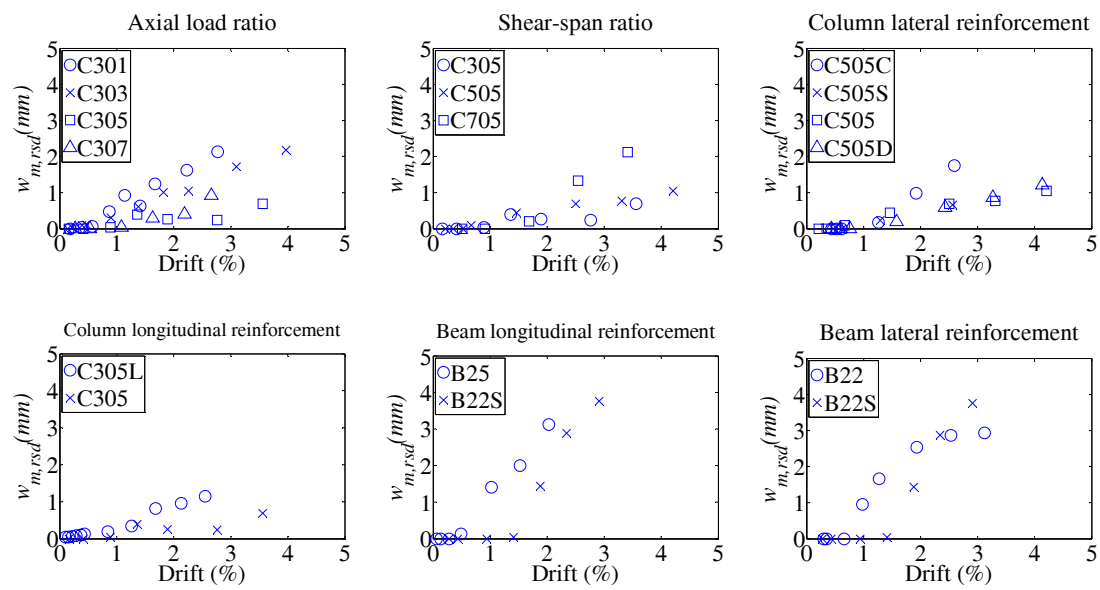

Figure 10: Maximum residual crack width of specimens.

Conceptually, the shear-span ratio reflects the quantity relationship between section moment and shear force. With the increasing shear-span ratio cracks reaching a larger width during the loading process and remaining larger when unloaded, it implies an increasing bending effect on columns.

The column lateral reinforcement seems to have little effect on cracking behaviour for the seismic-designed columns. However the maximum crack width and maximum residual width of specimen $\mathrm{C} 505 \mathrm{C}$, designed according to early 
non-seismic code, are much larger than those of seismic-designed columns. This may result from the weaken confinement for core concrete due to large hoop spacing. For the beams there seems to be a drift limit dividing the crack widthdrift curve into two sections. While the drift angle is below this limit, the more lateral reinforcement, the larger the maximum crack width and residual width. The situation is contrary while beyond this limit. Based on the limited test data, it may be found this limit drift is approximate to $2 \%$.

As illustrated in Figure 9 and Figure 10, larger diameter of column longitudinal rebars restrains the crack opening and promotes its closing. Contrary trend, although not very distinct, can be found for the beam specimens. Unfortunately little comparability exists between these two groups due to difference in sections, axial load level, shear-span ratio and so on.

\section{Conclusion}

In conclusion, the axial load ratio and shear-span ratio are the most important factors affecting column ductility. For the well-confined columns increasing lateral reinforcement ratio does not improve ductility evidently, neither does it for beams. Longitudinal reinforcement ratio also has limited effect on column ductility. However it has remarkable influence on beam ductility.

Effect of parameters on cracking behaviour is also discussed in this paper. The axial load ratio affects cracking behaviour most among these factors. With the increasing shear-span ratio cracks open in larger width and remain larger when unloaded. The lateral reinforcement seems to have little effect on cracking behaviour for the seismic-designed columns, and it influences beam ductility with drift-related characteristic. The effect of longitudinal reinforcing level on cracking behaviour needs more investigation.

\section{References}

[1] Structural Engineers Association of California, vision 2000: Performance based seismic engineering of buildings. Sacramento, California, 1995.

[2] Wang, Q., Zhao, G., \& Lin, L., Ductility of high strength reinforced concrete columns. Nuclear Engineering and Design. 156(1-2): pp. 75-81, 1995.

[3] Park, R. \& Paulay, T., Reinforced Concrete Structures. 1975, New York: John Wiley \& Sons.

[4] Code for Design of Concrete Structures, Construction Industry Publishing House of China: Beijing, 2002.

[5] Code for Seismic Design of Buildings, Construction Industry Publishing House of China: Beijing, 2002.

[6] Bae, S. \& Bayrak, O., Seismic performance of full-scale reinforced concrete columns. ACI Structural Journal. 105(2): pp. 123-133, 2008.

[7] Lam, S. S. E., et al., Drift capacity of rectangular reinforced concrete columns with low lateral confinement and high-axial load. Journal of Structural Engineering. 129(6): pp. 733-742, 2003. 
[8] Park, R., Priestley, M. J. N., \& Gill, W. D., Ductility of square-confined concrete columns. 108(ST4): pp. 929-950, 1982.

[9] Vintzileou, E. \& Stathatos, A., Assessment of the seismic behaviour of RC columns. Engineering Structures. 29(7): pp. 1296-1311, 2007.

[10] Park, R., Evaluation of ductility of structures and structural assemblages from laboratory testing. Bulletin of the New Zealand National Society for Earthquake Engineering. 22(3): pp. 155-166, 1989. 